\title{
Level of Stress in Parents of the Mentally Retarded Children
}

\author{
Article by Rubina K Benjamin \\ RN-MSN, Texila America University, Pakistan \\ E-mail: rubinabenjamin53@gmail.com
}

\section{Introduction}

Parenting is a challenging process. The crucial role of parents and family in caring, nurturing, protecting and socializing young children is well established across the cultures. Strong parent-child connectedness improves child academic outcomes, self esteem, mental health and has later protective effects of reducing the likelihood of alcohol and drug use in adolescence, high risk sexual behaviour and involvements in interpersonal violence (Lezin et al., 2004). Parenting can influence children's social, emotional, and academic adjustment, efforts have been made to determine factors that affect parenting behavior. One such factor is parenting stress. Parenting stress can be defined as excess anxiety and tension specifically related to the role of a parent and to parent-child interactions (Abidin, 1995). When the parents learn that the child is having some form of disability, it causes enormous distress to them. Giving birth to a mentally challenged children or other disabled child is an unexpected stressful event which affects the whole family. Such an event may impair family development and may continue over time affecting the entire family system. The presence of a mentally challenged child in the family has far reaching implication for the family as a whole. The impact of the disability and problem associated with it are not restricted to the child but extend far beyond the child and affects a number of areas of family functioning as well as individual's adjustment. Parents go through intense emotional and psychological stress and may have fewer resources of emotional gratification. They may consider mentally handicapped child as a threat to their self esteem and view themselves as a source of disability. They struggle to cope with the financial costs, parents also are confronted with new and unexpected experiences. Parents with disabled child may have higher levels of stress and lower levels of well being than with the normal children (Rangaswamy and Bhavani, 2008). In order to have better understanding of the factors that influence parenting stress which plays a crucial role in development of child both normal and challenged, the present study was undertaken with the objective to compare the level of stress among parents between normal and mentally challenged children

Mental retardation is one of the most prevalent developmental disabilities of the children globally. Family is the main source of support for those disable children in any society. Parents experience enormous physical and mental stress to tackle the mentally retarded child Once the parents come to realize that their child is mentally challenged; they are confronted with many challenges and problems. The nature of stress and areas of stress in parents of the mentally challenged have been studied extensively. Seth (1979) reported care stress and social stress in $83 \%$ of mothers, emotional stress in $80 \%$ of mothers and financial problem in $47 \%$ of mothers. Prabhu (1989) finds care stress, social stress and financial stress in parents. Venkatesan \& Das (1994) report that the type of burden reported by family members may range from difficulties in transportation of the child to the place of service delivery, management of behaviour problems, disruption of their daily routine, economic, physical and social burden. Pariante \& Carpiniello (1996) report more of emotional distress, poor social relationships and lack of holidays or free time. Various factors attributing to stress in such parents have been studied. Datta, Russell, Swamidas, Gopalakrishna \& Seetha (2002) find that expressed emotions toward the child, age of the child and income as important factors associated with burden. Gupta \& Jain (2002) find that less educated, low income group and rural parents have more problems with their spastic mentally handicapped children. In the present study, some of the child characteristics namely; gender, IQ, age, presence of 
behaviour problems, number of mentally challenged children in the family and number of siblings in the family are studied. Similarly, parent characteristics namely; age, education, income, rural-urban status, occupation and presence of grandparents are studied.en.

A mentally retarded child in a family is usually a serious stress factor for the parents. It often requires a reorientation and reevaluation of family goals, responsibilities and relationships. In India, the majority of persons with mental retardation have traditionally been cared for by their families. In today's modern society this home-based care has resulted in many adverse consequences. Factors such as changes in the social system (e.g. breaking up of joint families) and the economic system (e.g. unemployment, inflation, etc.) have contributed to the stress that parents of mentally retarded children experience.

The emotional and social stress that these parents undergo have been described by various investigators in the East and West..$^{-\frac{5}{5}}$ On the other hand, few studies have shown that stress is not an inevitable consequence in these parents. ${ }^{6,7}$ However, studies comparing the stress perceived by parents of mentally retarded and normal children are limited. Therefore, we undertook this study (i) to find any difference in the perceived stress between both the parents of mentally retarded children, (ii) to establish whether these stresses occur more frequently in parents of mentally retarded children than in those of normal children, and (iii) to find any correlation between the severity of perceived stressors and the anxiety state of these parents.

\section{Literature review}

A differential research design to compare the level of parenting stress of normal and mentally challenged children was undertaken on a sample of 30 mentally challenged children and 60 normal children of age group 5-10 years. Abidin's (1995) Parenting stress index- short form was used to assess the level of parenting stress. The results revealed that higher per cent of parents of mentally challenged had clinically significant parenting stress (73.4\%) than parents of the normal children (21.7\%)(NARMADA HIDANGMAYUM AND PUSHPA B. KHADI)

To find whether there exists a difference in the perceived stress between both the parents of mentally retarded children, to study whether these stresses occur more frequently in parents of mentally retarded children compared with those of normal children, and to find any correlation between the severity of perceived stressors and the anxiety state of these parents.

This study was conducted in the Child Guidance Clinic of a tertiary care psychiatry hospital. The study sample, comprising 180 subjects, was categorized as: group A (60 parents of profound to moderately mentally retarded children), group B (60 parents of mild to borderline mentally retarded children) and group C (60 parents of children with normal intelligence), which served as the control group. Each parent was evaluated using the Family Interview for Stress and Coping (FISC) in Mental Retardation, and the Hamilton Anxiety Rating Scale (HARS)

Parents in group A had a significantly higher frequency of stressors and level of anxiety as compared to those in groups B and C. A positive correlation was found between the level of anxiety and stressors. Multifaceted factors made parents in groups A and B more vulnerable to stress compared with parents in the control group.

Mental retardation is one of the most prevalent developmental disabilities of the children globally. Family is the main source of support for those disable children in any society. Parents experience enormous physical and mental stress to tackle the mentally retarded children. This present comparative cross-sectional study tried to compare difference of mental and physical stress between the parents of children with mental retardation and the parents of children with no mental retardation. It included 220 parents, 110 of whom had children with mental retardation and another 110 parents of children with no mental retardation. To assess stress, A Quick Stress Assessment Test (QSAT) (Vaz, 1995) was used, which comprised two parts: physical and mental, former with 19 items and latter with 21 items. Data were collected with a self-administered questionnaire and analyzed by using SPSS software. To check differences of stress scores and gender differences of stress, ' $\mathrm{t}$ ' test and ' $\mathrm{X}$ ', tests were applied 
as required. The study revealed that the parents of children with mental retardation (PCMR) shared significantly greater stress score (34.27) than the parents of children with no mental retardation (PCNR) (21.66), $\left[\mathrm{t}_{(218)}=2.63, \mathrm{p}=0.001\right]$. Mental stress score was significantly higher among PCMR (33.57) than the PCNR (26.46) $\left[\mathrm{t}_{(218)}=3.87\right.$; $\left.\mathrm{p}=0.002\right]$ while physical stress score was insignificantly higher among PCMR (20.43) than the PCNR (18.66). Majority of the parents with mentally retarded children (71.4\% mothers and $67.5 \%$ fathers) had higher mental stress than physical stress $\left[\mathrm{X}_{(1)}^{2}=22\right.$ 43, $\left.\mathrm{p}=0.024\right]$. Mothers had significantly higher mental stress score than the fathers of mentally retarded children [' $t$ ' ${ }_{(109)}$, $\mathrm{p}=0.025]$. Special measures like early diagnosis, prompt treatment and counseling for mental and physical stress of the parents along with provision of need based rehabilitation services for the mentally retarded children at different levels to reduce the stress burden of their parents. (Md Ziaul Islam, Sharmin Farjana, Runa Shahnaz)

\section{Objectives}

The objects of the study are:

- To find out the relationship between stress of parents with mentally retarded children

\section{Hypothesis}

H1: There is a significant relationship between stress of parents with mentally retarded children.

\section{Methodology}

\section{Sample}

The sample consisted of 100 caregivers was taken from children hospital of Lahore .The age range of the sample was 20 to 50 years.

\section{Sample strategy}

Convenient sampling technique was used for the study.

\section{Research design}

Co-relational research design was used as they find out the relationship between the variables(Oswald,2008).

\section{Instruments}

\section{Preceived stress scale}

The Perceived Stress Scale (PSS) was developed by Sheldon Cohen .it is the most widely used psychological instrument for measuring the perception of stress. It is a measure of the degree to which situations in one's life are appraised as stressful. Items were designed to tap how unpredictable, uncontrollable, and overloaded respondents find their lives. The scale also includes a number of direct queries about current levels of experience .The questions in the PSS ask about feelings and thoughts during the last month. In each case, respondents are asked how often they felt a certain way stress

PSS-10 scores are obtained by reversing the scores on the four positive items, e.g., $0=4$, $1=3,2=2$, etc. and then summing across all 10 items. Items $4,5,7$, and 8 are the positively stated items.

\section{Procedure}

First of all, I asked the head for permission for research work. Then I make each participant sit comfortably . After that I told them the purpose of my research. The test were applied on caregivers with patients in children hospital of Lahore. The tests which applied on participants were Perceived Stress Scale. The test were given to them in written form Subject were be asked to carefully readout each statement and mark the most suitable option, after completing all tests I checked each answer, in order to know if any statement had been left 
Texila International Journal of Academic Research

Volume 3, Issue 2, Dec 2016

unmarked. Time consumed for tests was approximately 15 to 20 minutes Subject were make sure the information provided by them would be kept confidence and will not be disclosed to others at the end. I personally thank each subject and their head for their corporation.

\section{Statistical analysis}

Appropriate Statistical Analysis was carried out by using Pearson product-moment correlation coefficient to find out the relationship of mental retardation of children with stress of their parents.

\section{Results}

Hypothesis 1

Table 4.2

Pearson Product Moment correlation finds out the relationship between stress of parents and mentally retarded children.

\begin{tabular}{lll}
\hline $\mathrm{N}$ & $\mathrm{r}$ & $\mathrm{Sig}$ \\
\hline 100 & -.112 & 269 \\
\hline
\end{tabular}

Note: $\mathrm{P}>0.01$

\section{Discussion}

Nature of stress: The fathers and mothers are studied separately to find the difference between them in their perception of stress. The mothers experience higher stress than the fathers (Table 1). Heller, Hsieh and Rowitz (1997) report higher stress in mothers. When different areas of stress are considered, it is noticed that the mothers are stressed more compared to the fathers in daily care, emotional and social stress (Figure 1). Regarding financial stress, there is no difference between fathers and mothers. Most of the fathers and mothers have reported mild and moderate levels of stress (Table 2). The regression analysis for areas of stress indicates that all areas of stress are contributing significantly to the total stress for fathers and mothers. Care stress: Some parents report no stress regarding daily care. The reason may be that, some mentally challenged children are not causing any problem and also some parents may not feel the burden of care. It is noticed that for fathers disturbed behaviour and extra inputs of care are the prominent factors of care stress, the other one being decreased leisure time. For mothers, decreased leisure time and extra inputs of care are the major factors and the other one is disturbed behaviour (Table 3). Sequeira, Rao, Subbakrishna and Prabhu (1990) report disruption in the family routine. Venkatesan (2003) reported that disciplining and management of problem behaviours in their children appear to be the major source of burden. Family-emotional stress: Fathers and mothers have moderate emotional stress and stress is more in mothers compared to the fathers (Figure 1). The important finding is that fathers and mothers have reported effect on siblings equally as a major factor in personal emotional stress (Table 3). Emerson, Robertson and Wood (2004) found elevated psychological distress in 47\% of the parents. Fisman, Wolf, Ellison and Freeman (2000) finds more adjustment problems in siblings of the retarded. Fahey (2005) finds positive adaptation in the siblings of the retarded. In the present study, it is seen that parents report negative effect on siblings. Social stress: Mothers report higher social stress than fathers (Figure 1). Gumz and Gubrium (1972), and McAllister, Butler and Lie (1973) noticed social stress. Financial stress: Majority of parents report moderate financial problems and stress level is similar for fathers and mothers (Figure 1). Datta, Russell, Swamidas, Gopalakrishna and Seetha (2002) report income as an important factor in stress. Factors of stress: Each factor is discussed separately as to whether it influences stress experienced by parents of mentally retarded individuals. Statistical details are not mentioned regarding those factors, which do not appear as significant. 